\title{
Status loss due to COVID-19, traditional masculinity, and the prediction of suicidal ideation and recent suicide attempts
}

\author{
Walther, A. ${ }^{1,}{ }^{*}$, Grub, J. ${ }^{1}$, Tsar, S. ${ }^{1}$, Ehlert, U. ${ }^{1}$, Heald, A. ${ }^{2,3}$, Perrin, R. ${ }^{4}$, Ogrodniczuk, J.S. ${ }^{5}$, \\ Seidler, Z.E. ${ }^{6,7}$, Rice, S.M. ${ }^{6,7}$, Kealy, D. ${ }^{5}$, Oliffe, J.L. ${ }^{8,9}$, Eggenberger, L. ${ }^{1}$ \\ ${ }^{1}$ Clinical Psychology and Psychotherapy, University of Zurich, Zurich, Switzerland \\ ${ }^{2}$ The School of Medicine and Manchester Academic Health Sciences Centre, University of Manchester, UK \\ ${ }^{3}$ Department of Endocrinology and Diabetes, Salford Royal Hospital, Salford, UK \\ ${ }^{4}$ The School of Health Sciences, University of Manchester, Manchester, UK \\ ${ }^{5}$ Department of Psychiatry, University of British Columbia, Vancouver, Canada \\ ${ }^{6}$ Orygen, Melbourne, VIC, Australia \\ ${ }^{7}$ Centre for Youth Mental Health, The University of Melbourne, Parkville, VIC, Australia \\ ${ }^{8}$ School of Nursing, University of British Columbia, Vancouver, Canada \\ ${ }^{9}$ Department of Nursing, University of Melbourne, Parkville, VIC, Australia \\ * corresponding author
}

Manuscript word count: 5’870

Abstract word count: 234

References: 55

Tables: 1

Figures: 4

Supplementary material: Provided (S-Table 1 and S-Table 2)

Correspondence to: Dr. Andreas Walther, Binzmühlestrasse 14, 8050, Zürich; Clinical Psychology and Psychotherapy, University of Zurich, Zurich, Switzerland

a.walther@psychologie.uzh.ch 


\section{Abstract}

Background: The COVID-19 pandemic is causing extensive job loss leading to a loss of social status in many men. Endorsement of traditional masculinity ideology may render some men particularly sensitive to status loss and thereby to an increased risk for suicidality.

Methods: In this anonymous online survey conducted in German-speaking European countries, 490 men completed questionnaires regarding loss of social status due to the pandemic, suicidal ideation and past-month suicide attempt. Furthermore, prototypical and male-typical externalizing depression symptoms, self-identified masculine gender orientation, endorsement of traditional masculinity, and gender role conflict were measured.

Results: Out of a total of 490 men, $14.7 \%$ of men reported experiencing a status loss due to the pandemic. These men were more than twice as likely to report suicidal ideation during the past two weeks, and more than four times as likely to have attempted suicide in the past month than men not reporting a status loss. Depression symptoms, self-identified masculine gender orientation, endorsement of traditional masculinity, but not gender role conflict were positively associated with status loss. Suicidal ideation and suicide attempt were associated with prototypical and male-typical externalizing depression symptoms, but not masculinityrelated constructs.

Conclusion: Status loss emerges as risk factor for suicide and is associated with depression symptoms, higher masculine gender orientation and endorsement of traditional masculinity. Men with high levels of traditional masculinity and status loss due to the pandemic are at increased risk for suicide.

Key words: COVID-19; suicide attempt; suicidal ideation; traditional masculinity; depression 


\section{Introduction}

The COVID-19 pandemic is a crisis with ongoing and emergent intertwining health and economic implications. The health crisis aspect of the COVID-19 pandemic, inclusive of various lockdown measures implemented to mitigate the spread of the virus, has caused wide-spread psychological distress (Benke et al., 2020; Ozamiz-Etxebarria et al., 2020; Salari et al., 2020). Individuals with pre-existing mental health problems have been especially vulnerable, with many being at increased risk for suicide (Sher, 2020). Economic crises are historically been accompanied by financial difficulties, job loss, insecurity and underemployment, which all can act as risk factors for heightened suicide rates in those affected (Nordt et al., 2015). Therefore, elevated rates of job loss, bankruptcy declarations by businesses, and a substantial increase in suicide rates has also been predicted for the COVID-19 pandemic and its aftermath (Kawohl \& Nordt, 2020). Indeed, first results show that several COVID-19 related experiences such as social distancing are associated with increased risk for past-month suicidal ideation and suicide attempt (Ammerman et al., 2021) and that recent job loss due to COVID-19 is associated with heightened suicide risk (Griffiths et al., 2021).

Previous studies suggested that unemployment and suicide are more strongly associated in men than women (Blakely et al., 2003; Garcy \& Vågerö, 2013; Martikainen \& Valkonen, 1996), as is the relation between low income and suicide (Sher, 2006). Men as compared to women also exhibit higher levels of depression or shame after involuntary job loss (Andreeva et al., 2015; Rantakeisu et al., 1997). This may be related to the fact that the most important non-pecuniary cost of involuntary job loss and unemployment is the loss of social status (Creed \& Macintyre, 2001; Paul \& Batinic, 2010). Traditional masculinity characterized by dominance, pursuit of status, primacy of work, and self-reliance contrasts the loss of social status that occurs from involuntary job loss or underemployment. In addition to the psychological distress due to involuntary job loss and the associated status loss, men therefore additionally experience gender role conflict (O'Neil, 2013). Gender role conflict is a psychological state in which socialized, often rigid gender roles have negative consequences for the person if they are unable to attain these standards. For example, involuntary job loss directly conflicts with the rigid male role norm of "pursuit of status", resulting in the potential for heightened feelings of shame, guilt, failure and overall subordinate status (Eales, 1989; O'Neil, 2015; Rantakeisu et al., 1997). Further support for this finding stems from studies highlighting that men as compared to women estimated low appraisals of their own status by 
others after a job loss (Michniewicz et al., 2014) and studies indicating that status loss, and not low socioeconomic status per se, leads to suicidality in men (Dombrovski et al., 2018; Lewis \& Sloggett, 1998).

Social status rooted in the work role, which for many men offers purpose, routine and reinforces the positively connoted role of provider and protector, is essential to masculine identity as well as control over their own environment and work (Levant \& Richmond, 2015; O'Neil, 2015). Therefore, men appear especially vulnerable with regard to achievement and occupational stressors and feelings of powerlessness due to ingrained masculine ideals (Siegrist, 2000). As men can experience profound social status loss with un- or underemployment amid feeling powerless to improve their situation, they commonly experience loss of control, helplessness, and depression (Andreeva et al., 2015; Tiggemann \& Winefield, 1984). This in turn adversely affects men's masculine identity. Vandello and Bosson (2013) experimentally showed that after experiencing masculinity threats men tend to find ways to restore it by dismissing or denying masculinity threatening information, emphasizing one's masculine traits, or using group-based prejudices for one's own masculinityenhancement (Dahl \& Cook, 2020; Vandello \& Bosson, 2013). Many men react with maladaptive coping strategies rooted in traditional masculine role norms leading to substance misuse, aggressive, risky, or suicidal behavior, as well as reluctance to seek counseling (Bosson \& Vandello, 2011; Eggenberger et al., 2021; Rice et al., 2019; Walther et al., 2021; Walther \& Seidler, 2020).

In addition to status loss, the level of endorsement of traditional masculinity ideology is important for the prediction of suicide in men. Recently reported were men with high endorsement of traditional masculinity to be more than twice as likely to die by suicide as compared to men with low traditional masculinity (Coleman et al., 2020). Adherence to the traditional masculine role norm of self-reliance was further associated with increased risk for suicidal ideation (Pirkis et al., 2017). Conformity to traditional male role norms is generally associated with worse mental health outcomes and reduced help-seeking (Wong et al., 2017) or delayed psychotherapy use (Eggenberger et al., 2021). Furthermore, high endorsement of traditional masculinity ideology can lead men to exhibit male-typical externalizing depression symptoms such as anger and aggression, substance misuse, and/or risk taking, which can increase the risk for suicide and complicate its detection for health services who's diagnostic 
tools do not focus on these behaviors (Rice et al., 2013; Walther et al., 2021; Walther \& Seidler, 2020).

Taken together, men who endorse traditional masculinity are more likely to experience male-typical externalizing depression symptoms and suicidality in connection with status loss. Nevertheless, it is important to note that there is a growing body of evidence suggesting that certain masculine traits or norms can act as protective factors for men's wellbeing or are unrelated to mental health (Gerdes \& Levant, 2018; Lin et al., 2021; Van Doorn et al., 2021), while the rigid adherence to traditional masculinity is in general linked to worse mental health and health behaviors (Lippa et al., 2000; Mahalik et al., 2021; Wong et al., 2017). However, traditional masculinity ideology has never been investigated as potential moderator of the association between experienced loss of social status and suicide risk in men.

Investigating suicide risk in men in relation to COVID-19 pandemic related status loss and traditional masculinity emerges as highly relevant as many men report a deterioration of their financial situation, as well as their mental health with a high proportion reporting suicidal ideation due to the COVID-19 pandemic (Ogrodniczuk et al., 2021). In the present study, we examine the relations between loss of social status due to the COVID-19 pandemic, suicidal ideation and past-month attempted suicide in men, and whether masculine gender role orientation, endorsement of traditional masculinity ideology, and gender role conflict moderate these associations.

\section{Methods}

\subsection{Procedure and Samples}

This pre-registered anonymous, cross-sectional online survey was approved by the local ethics committee of the Faculty of Arts and Social Sciences of the [blinded] (Authorization No. 21.2.4). According to the Open Science standards a priori defined study hypotheses, statistical analyses, and the study specific data set can be retrieved from OSF (osf-link / currently still embargoed / release 2021/12/31). For the recruitment of male participants, the study was distributed through advertisements on social media platforms and the study's webpage. Advertisements on social media platforms were restricted to men of 18 years or older in the countries Germany, Switzerland, Austria, Lichtenstein, Luxembourg, and Belgium. All men, irrespective of mental health status, were eligible to participate. The goal was to recruit a large sample of men older than 18 years with sufficient German language skills to 
read and respond to the questionnaire in German language. During the recruitment period from March $15^{\text {th }} 2021$ to April $28^{\text {th }} 2021$ a total number of 1087 people expressed interest in this study by visiting the starting page of the online questionnaire. A little more than half of the initially interested participants $(597,54.92 \%)$ were not included in the final analyses for one of the following reasons: data privacy agreement not provided, declaration of consent not provided, self-reported insufficient German language skills, gender requirements not fulfilled, age of minority and/or incomplete data in the questionnaires. This resulted in a total number of 490 participants included in the current analyses. Figure 1 presents the participant flow diagram. Participants provided written informed consent at the beginning of the survey and agreed to the data privacy statement prior to answering sociodemographic questions, COVID-19-related questions and a set of psychometric instruments. Completion time for the survey part included in this study was 20 minutes. However, participants then went on to participate in further online-experiments, which are beyond the scope of this report.

\subsection{Instruments}

2.2.1. Sociodemographics, social status, and COVID-19 related questions

At the beginning of the online survey, participants answered sociodemographic questions assessing sufficiency of German skills, gender, dimensional gender (positioning between the two poles 1 = masculine, 10 = feminine), age, height, weight, nationality, relationship status, sexual orientation, and education. Further, the household's yearly gross income was assessed. To measure social status, participants were asked to estimate their subjective social status on the MacArthur-Scale of Subjective Social Status in their own social environment (Euteneuer et al., 2015). Participants were presented with a picture of a vertical ladder with ten Steps (1-10) and introduced to it with the following text: "Imagine that this ladder shows where people stand in their social environment. At the top of the ladder are people who are at the highest level in their social environment. At the bottom of the ladder are people who have the lowest standing in their social environment. Where would you place yourself on the ladder?" Participants were then instructed to indicate the step of the ladder they are currently standing in comparison to other people in their social environment. The convergent and discriminant correlation analyses of the German-language version in the present study and previously reported (Euteneuer et al., 2015) are consistent with findings from the English-language context (Cundiff et al., 2013; Operario et al., 2004) showing 
significant positive correlations with education, income, optimism and martial satisfaction and significant negative correlations with neuroticism or depression symptoms supporting the construct of subjective social status related to one's own environment. Good six-month testretest reliability $(\rho=0.62)$ was previously reported in a longitudinal design (Operario et al., 2004). In addition, men were subsequently asked whether they experienced a loss of social status due to the COVID-19 pandemic in a dichotomous form (yes/no) and when answering "yes", they were further asked to indicate how many steps on the depicted ladder (MacArthur-Scale) they moved towards the bottom with the response options 1 till 10 . Participants were further asked whether they had attempted suicide in the past month, or lifetime. Two items directly asking about suicide attempts were used with the following format for past-month suicide attempt: "Have you attempted to commit suicide in the last month? Has there been a situation in the last 30 days where you deliberately and intentionally harmed yourself or put yourself in such danger that your life was in danger? Or would other people such as doctors or family members say that you have attempted suicide in the last 30 days?". Suicidal ideation during the past two weeks was assessed by a single item asking about how often one was bothered by "thoughts of preferring to be dead or wanting to inflict harm on oneself" over the last two weeks, which has previously been shown to be a valid assessment of suicidal ideation (Louzon et al., 2016; Na et al., 2018). This item was subsequently dichotomized into two categories comprised of participants either having had suicidal ideation (considering answers $1-3$, regardless of their frequency) or having not had suicidal ideation in the past two weeks (only considering the answer 0 ).

Further, participants were asked whether they were currently suffering from a mental disorder, and in case of a positive answer, of which mental disorder in particular (13 mental disorders listed, and the additional option of specifying one not listed, multiple naming possible). Additionally, participants were asked to indicate whether they were currently undergoing psychotherapeutic treatment and whether they were currently taking psychopharmacological drugs.

Assessing further difficulties caused by the COVID-19 pandemic in addition to social status loss included a set of questions asking about experienced financial losses, job insecurity, job loss, need to consult an employment office, existential threat, social contact loss, and physical contact loss. 
2.2.2. Bem Sex-Role Inventory - Masculinity (BSRI-M)

The Bem Sex Role Inventory (Bem, 1974) measures masculinity and femininity independently as a two-dimensional construct, consisting of a masculinity and a femininity scale. Each scale contains personality characteristics or traits that were selected as masculine or feminine based on sex-typed social desirability (Bem, 1974). For the present study, a validated German version of the 30-item short version by Bem was used (Troche \& Rammsayer, 2011). Only the masculinity subscale BSRI-M was used to identify the degree of self-identified masculine gender orientation (Cronbach's $\alpha=.83$; Troche \& Rammsayer, 2011). For the 15 items of the masculinity scale, the participants had to specify how well the item matches their self-perception on a seven-point Likert scale ranging from 1 (never or almost never true) to 7 (always or almost always true). Cronbach's $\alpha$ in the current study was 0.90 .

\subsubsection{Male Role Norm Inventory - Short Form (MRNI-SF)}

The Male Role Norms Inventory - Short Form (MRNI-SF; Levant et al., 2013) is a 21item instrument that measures with seven subscales norms of traditional masculinity ideology. Participants are asked to indicate the extent to which they agree with traditional masculinity ideology statements on a seven-point Likert scale $(1=$ strongly disagree, 7 = strongly agree). The seven subscales represent the following dimensions: restrictive emotionality, self-reliance through mechanical skills, negativity toward sexual minorities, avoidance of femininity, importance of sex, dominance, toughness. For the original English version of the MRNI-SF, Cronbach's alpha of $\alpha=.92$ for men has been reported (Levant et al., 2013). Cronbach's $\alpha$ in the current study are as followed: MRNI-SF total score $=0.94$, MRNISF negativity toward sexual minorities $=0.87$, MRNI-SF restrictive emotionality $=0.74, \mathrm{MRNI}-$ SF self-reliance through mechanical skills $=0.88, \mathrm{MRNI}-\mathrm{SF}$ avoidance of femininity $=0.88$, MRNI-SF importance of sex $=0.88, \mathrm{MRNI}-\mathrm{SF}$ dominance $=0.88, \mathrm{MRNI}-\mathrm{SF}$ toughness $=0.81$.

\subsubsection{Gender Role Conflict Scale - Short Form (GRCS-SF)}

The Gender Role Conflict Scale (O'Neil et al., 1986) was developed to measure patterns of gender role conflicts. The Gender Role Conflict Scale - Short Form (GRCS-SF; Wester et al., 2012) measures four patterns of gender role conflict: 1) success, power, and competition $(\mathrm{SPC}), 2$ ) restrictive emotionality $(\mathrm{RE}), 3)$ restrictive affectionate behavior between men (RABBM), and 4) conflict between work and family relations (CBWFR). The GRCS-SF consists 
of 16 items, whereby four items are dedicated to each of these patterns of GRC. The participants are asked to indicate the degree of experienced conflict on a six-point Likert scale ( 0 = strongly disagree, 5 = strongly agree). Wester et al. (2012) reported internal consistencies of $\alpha=0.77-0.80$. In the present study the German version of the Gender Role Conflict Scale - Short Form (Komlenac et al., 2018) was used. Cronbach's $\alpha$ in the current study was 0.79.

\subsubsection{Patient Health Questionnaire-9 (PHQ-9)}

The Patient Health Questionnaire (Kroenke et al., 2001) assesses nine symptoms of major depressive disorder specified by the Diagnostic and Statistical Manual of Mental Disorders (DSM-5; American Psychiatric Association, 2013). For each of the nine symptoms, participants rate how often those appeared within the preceding two-week period on a fourpoint Likert scale ranging from 0 (not at all) to 3 (almost every day). The PHQ-9 item nine, asking about how often one was bothered by thoughts that one would be better off dead or hurting oneself over the last two weeks, was used to assess past-two-week suicidal ideation. The PHQ-9 is further used to make criteria-based diagnoses of depressive disorders with a cutoff $\geq 10$ within research and clinical practice (Levis et al., 2020) and has shown to provide a reliable and valid measure of depression severity (Kroenke et al., 2001). A German version of the PHQ-9 was used in this study, which has been previously validated on a representative German-speaking sample (Cronbach's $\alpha=0.89$; Martin et al., 2006). Cronbach's $\alpha$ in the current study was 0.90 .

\subsubsection{Male Depression Risk Scale-22 (MDRS-22)}

The Male Depression Risk Scale (Rice et al., 2013) includes 22 items assessing externalizing depressive symptoms within the preceding month, which are rated on an eightpoint Likert scale ranging from 0 (not at all) to 7 (almost always). The scale considers genderspecific externalizing symptoms of depression and assesses men's depression symptoms within the context of cultural norms related to masculinity. The six domains of the MDRS-22 include emotion suppression (i.e., "I bottled up my negative feelings"), drug use (i.e., "I used drugs to cope"), alcohol use (i.e., "I needed to have easy access to alcohol"), anger and aggression (I.e., "I overreacted to situations with aggressive behaviors"), somatic symptoms (i.e., "I had regular headaches") and risk-taking (i.e. "I took unnecessary risks"). The MDRS-22 is further used to identify clinically relevant male depression syndrome based on a cut-off $\geq$ 
51. In the present study the validated German version of MDRS-22 was used (Guttman's $\lambda 2=$ 0.62-0.91; Walther et al., 2021). Cronbach's $\alpha$ in the current study was 0.88 .

\subsection{Statistical analysis}

All computations and analyses were conducted in the R software environment (R Core Team, 2020) with the additional packages "car" (Fox \& Sanford, 2019; used for variance inflation factors), "ggplot2" (Wickham, 2016; used for visualizations), "psych" (Revelle, 2020; used for calculating internal consistencies and effect sizes), and "rcompanion" (Mangiafico, 2021; used for maximum-likelihood estimations of logistic regression model indices). All analyses and calculations were controlled for the participants' age, income, educational level, and sexual orientation as covariates. Furthermore, an alpha-level of $\alpha=.05$ was used consistently throughout all analyses when testing for significant results. Lastly, statistical assumptions for the analyses described in the following were tested using Levene's test for equal variances (Brown \& Forsythe, 1974), Fox and Monette's (Fox \& Monette, 1992) generalized variance inflation factor to assess collinearity of predicting variables, and Cook's distance (Cook, 1977) to detect highly influential points in the logistic regression models.

Sample characteristics were determined by calculating summary statics for the relevant variables. Two-sided $t$-tests and two-sided chi-square tests were used to test for group differences between the two subgroups obtained by splitting the sample into men who reported having experienced a status loss due to the COVID-19 pandemic, and men who reported not having experienced a status loss due to the pandemic. Subsequently, binomial logistic regression analyses were conducted to test the predictive value of prototypical and male-typical externalizing depression symptoms (PHQ-9 and MDRS-22), traditional masculinity ideologies (BSRI and MRNI), and gender role conflict (GRCS) for the likelihood of having experienced status loss, having attempted suicide, and having had suicidal ideation. For these analyses, effect sizes were calculated in the form of standardized mean differences (Cohen's $d$ ) and standardized odds ratios. Finally, explorative interaction analyses were conducted following the regression-based approach proposed by Hayes (Hayes, 2013) to assess possible conditional relations between status loss, traditional masculinity and suicide attempts.

\section{Results}




\subsection{Descriptive Statistics and Group Differences separated by Status loss}

A total of 490 male respondents ranging in age from 18 to 68 years old ( $M$ 25.7; SD=9.7) completed the survey questionnaire. As shown in Table 1, $14.7 \%$ of men $(n=72)$ indicated having experienced a status loss due to the COVID-19 pandemic. A total of 20 men (4.1\%) reported past-month suicide attempt, while 114 (23.3\%) reported having suffered a suicide attempt in their past. Suicidal ideation during the past two weeks was reported by 240 men (49\%). For further descriptives of the sample see Table 1.

Significant group differences emerged when comparing men's status loss (Figure 2, Table S1). Regarding suicide attempts (past month / lifetime) and suicidal ideation (past two weeks) (Figure 2A), significantly more men who experienced status loss attempted suicide in the past month $(11.1 \%)$ and in their lifetime $(33.3 \%)$ as compared to men who have not experienced status loss (suicide attempt past month: $2.9 \%, \mathrm{OR}=4.4$ [1.6 - 11.4]; standardized $\mathrm{OR}=1.7$ [1.2 - 2.4]; suicide attempt lifetime: $21.5 \%, \mathrm{OR}=1.8$ [1.0 - 3.1]; standardized $\mathrm{OR}=1.2$ [1.0 - 1.5]). Furthermore, men who have experienced status loss were also significantly more likely to report past-two-week suicidal ideation (65.3\%) compared to men who have not experienced status loss (46.2\%, OR = $2.4[1.4-4.2]$; standardized OR $=1.4[1.1-1.7])$.

Regarding mental health and traditional masculinity ideologies (Figure 2B), men who experienced status loss due to the COVID-19 pandemic also showed significantly higher prototypical depression symptoms (PHQ-9, $d=0.6[0.9-0.4])$ and male-typical externalizing depression symptoms (MDRS-22, $d=0.8[1.1-0.6]$ ) as compared to men who have not experienced status loss. Furthermore, as shown in Figure 2, men who have experienced status loss also reported significantly higher self-identified masculine gender role orientation (BSRI$\mathrm{M}, d=0.3[0.5-0.1]$ ), higher traditional masculinity ideologies (MRNI-SF, $d=0.6[0.3-0.9]$ ), and they exhibited significantly higher gender role conflict (GRCS, $d=0.7$ [0.4 - 0.9]) as compared to men who have not experienced status loss.

\subsection{Binary Logistic Regression Analysis for the Prediction of Status loss, Suicide} Attempts (past-month / lifetime), and Suicidal Ideation (past two weeks)

Binary logistic regression analyses fitted to predict status loss, suicide attempts, and suicidal ideation based on depression symptoms and traditional masculinity concepts yielded additional significant results (Figure 3, Table S2). Higher likelihood for status loss was 
significantly associated with higher prototypical (standardized OR $=1.9[1.3-2.8]$ ) and higher male-typical externalizing depression symptoms (standardized OR = 1.4 [1.0 - 1.9]), higher selfidentified masculine gender orientation (standardized OR = $1.5[1.1-2.0]$ ), and higher traditional masculinity ideologies (standardized OR = 1.4 [1.1 - 1.9]) (Figure 3A).

Furthermore, the likelihood of having attempted suicide in the past month was significantly associated with increased prototypical (standardized OR = 2.6 [1.2 - 5.8]) and male-typical externalizing depression symptoms (standardized OR $=2.0[1.3-3.5]$ ) (Figure 3B). On the other hand, the likelihood of lifetime suicide attempt was only significantly associated with higher prototypical depression symptoms (standardized $\mathrm{OR}=2.0[1.4-2.8]$ ) but not with male-typical externalizing depression symptoms (standardized OR = 1.7 [0.9 - 1.7]) (Figure 3C). The likelihood for exhibiting suicidal ideation in the past two weeks was significantly associated with higher traditional (standardized $\mathrm{OR}=5.5[3.6-8.5]$ ) and externalizing depression symptoms (standardized OR = 1.5 [1.0 - 2.2]) (Figure 3D).

\subsection{Interaction Analysis Examining Conditional Relations between Status loss,} Traditional Masculinity, Suicide attempts (past month), and Suicidal Ideation (past two weeks)

Interaction analyses yielded one significant interaction (Figure 4). For past-month suicide attempt, men with a high self-identified masculine gender orientation and who experienced loss of social status were more likely to have attempted suicide in the past month (standardized OR $=0.4[0.1-0.9]$ ) (Figure 4A). Similarly, when status loss was used as a dimensional variable (where $0=$ no status loss and increasing values above $1=$ increasingly severe status loss), the same significant interaction suggests that men who report a stronger fall on the status ladder and who exhibit a high self-identified masculine gender orientation would be at an increased risk for attempting suicide (Figure 4B).

\section{Discussion}

\subsection{Summary of results}

The present study aimed to examine the relation between an experienced loss of status due to the COVID-19 pandemic and its potential in predicting past-two-week suicidal ideation and past-month suicide attempt among men. Furthermore, potential associations between status loss due to the COVID-19 pandemic and self-identified masculine gender 
orientation, endorsement of traditional masculinity ideology, and gender role conflict were investigated. The 72 men (14.7\%) having experienced a status loss due to the COVID-19 pandemic were significantly more likely to exhibit past-two-week suicidal ideation and pastmonth as well as lifetime suicide attempts. Effect sizes suggest small to medium effects for the association between status loss and suicidal ideation and lifetime suicide attempt and a medium to large effect for the association between status loss and past-month suicide attempt (Chen et al., 2010). Men having experienced a status loss due to the pandemic also showed increased levels in prototypical (PHQ-9) and male-typical externalizing (MDRS-22) depression symptoms with medium to large effect sizes. Furthermore, men having experienced a status loss consistently scored higher on all three masculinity measures, namely self-identified masculine gender orientation (small effect), endorsement of traditional masculinity ideology (medium effect), and gender role conflict (large effect).

Logistic regressions revealed that status loss was significantly predicted by masculine gender orientation, endorsement of traditional masculinity ideology, prototypical depression symptoms, and male-typical externalizing depression symptoms, but not by gender role conflict. For past-two-week suicidal ideation and past-month suicide attempt, only the depression scales measuring prototypical and male-typical externalizing depression symptoms emerged as significant predictors. Finally, interaction analysis examining the potential moderating effect of masculinity constructs on the association between status loss and past-month suicide attempt revealed a consistent pattern with masculine gender orientation a significant moderator suggesting that men with a high masculine gender orientation and a status loss due to the COVID-19 pandemic are at increased risk for pastmonth suicide attempt.

\subsection{Integration of findings}

Several COVID-19-related experiences, such as general distress, fear of physical harm, or effects of social distancing policies have been positively associated with past-month suicidal ideation and suicide attempts (Ammerman et al., 2021). Furthermore, recent job loss or income loss due to the COVID-19 pandemic were related to poor mental health (Griffiths et al., 2021; Hertz-Palmor et al., 2021), and suicide risk (Gratz et al., 2020). However, the predictive potential of subjectively experienced loss of social status, identified as the most important non-pecuniary consequence of job loss (Creed \& Macintyre, 2001; Paul \& Batinic, 
2010), on past-two-week suicidal ideation and past-month suicide attempt in an exclusively male sample has not been investigated.

With $14.7 \%$ of men in the current sample having experienced a status loss due to COVID-19, the socioeconomic toll of the pandemic on the general population is reflected. Our results corroborate reports showing high rates of recent job loss due to COVID-19 of $11 \%$ (Gratz et al., 2020) and experienced income loss in 19\% (Hertz-Palmor et al., 2021). However, the studies by Gratz et al. (2020) and Hertz-Palmor et al. (2021) were conducted in the US and Israel and one year earlier than the data collection of the present study being carried out in German speaking countries of Europe (e.g., Germany, Switzerland, Austria), which explains differences in the identified percentage of men with a job-loss due to the COVID-19 pandemic of $8.4 \%$ and financial problems due to the COVID-19 pandemic of $20.4 \%$. Furthermore, the prevalence of past-month suicide attempt of $4.1 \%$ in the present sample confirms results of a prior study of a past-month suicide attempt prevalence of $4.9 \%$ in a mixed-gender sample (Ammerman et al., 2021). By contrast, in male sample surveyed prior to the pandemic outbreak, a past-month suicide attempt prevalence of 1.3\% was observed (Rice et al., 2019), highlighting the potential for increased suicide risk due to the COVID-19 pandemic.

The identified 2.4-fold increased risk of exhibiting past-two-week suicidal ideation and 4.4-fold increased risk of reporting a past-month suicide attempt in men experiencing a loss of social status due to the COVID-19 pandemic underline the pivotal role of social status loss in men with regards to suicide risk. For many men, in defining one's masculine self-concept against a set of rigid ideals (e.g., dominance, pursuit of status or primacy of work), the impact of losing one's job and perceived social status could understandably threaten their self-worth (Dahl \& Cook, 2020; Vandello \& Bosson, 2013). Our current findings suggest this perceived loss of social status links with heightened depression symptoms or dysfunctional externalizing coping behaviors in men such as elevated alcohol or drug use or risk taking, thus increasing the risk for suicide.

Conversely, logistic regression analysis confirmed that loss of social status due to COVID-19 pandemic was significantly predicted by the two depression measures (PHQ-9 and MDRS-22), while also having been predicted by self-identified masculine gender orientation (BSRI-M) as well as endorsement of traditional masculinity (MRNI-SF), but not by gender role conflict (GRCS). While job loss and status loss have consistently been associated with depression (Iñiguez et al., 2018; Riumallo-Herl et al., 2014), the current findings confirm our 
a priori preregistered hypothesis that high traditional masculinity predisposes men to loss of social status due to the COVID-19 pandemic. In times of an economic crisis as the COVID-19 pandemic, many individuals experience a loss of social status. Men with high traditional masculinity seem to be particularly affected due to the central role a job or social status in general plays in the masculinity self-concept. However, past-two-week suicidal ideation and past-month suicide attempt were not predicted by any masculinity measure. This corroborates a recent longitudinal study conducted over 19 years showing that men with high traditional masculinity as compared to men with low traditional masculinity were 2.4-times more likely to die by suicide, but 1.45-times less likely to report suicidal ideation, and not to differ with regard to suicide attempts (Coleman et al., 2020). Unfortunately, men adhering to traditional male role norms of restrictive emotionality or self-reliance and avoidance of femininity, generally report lower psychological distress levels (Mirowsky \& Ross, 1995). Therefore, self-report studies can only approximate the actual psychological symptom severity in men and "hard" outcome measures such as survival rate differentiated by suicide are preferred to examine the link between high traditional masculinity and suicide (Coleman, 2015; Coleman et al., 2020). Nevertheless, based on the present findings, a hierarchical organization of the examined constructs is supported, where traditional masculinity predicts loss of social status due to the COVID-19 pandemic and experienced loss of social status predicts suicidal ideation and suicide attempt.

This proposed flow of association from traditional masculinity, experienced loss of social status, and risk of suicide is further supported by the results of our moderation analyses. However, only one association emerged as significant. The association between loss of social status and past-month suicide attempt was moderated by masculine gender role orientation. As shown in Figure 4B higher self-identified masculine gender role orientation increased the positive association between experienced loss of social status due to the COVID-19 pandemic and past-month suicide attempt. This relationship is not readily interpretable due to Bem's conceptualization of masculinity via the BSRI-M (Bem, 1974). In contrast to the gender role strain paradigm reflected by the MRNI-SF (Levant \& Richmond, 2015), studies using the BSRI have mostly reported higher masculine gender orientation to be positively associated with self-esteem and self-confidence and negative with depression and anxiety symptoms (Johnson \& McCoy, 2000; Long, 1986; O'Heron \& Orlofsky, 1990). Considering that the BSRI$M$ conceptualizes masculinity as a set of socially desirable personality traits such as powerful, 
fearless or dominant that are regarded as characteristic of men, on the one hand it is surprising that men with experienced status loss have higher BSRI-M scores and that higher masculine gender orientation intensifies the association between status loss and past-month suicide attempt. On the other hand, this also highlights that men with higher BSRI-M may strive more for status while also being more sensitive to its loss. This is supported by work showing that men's endorsement of strict masculinity norms is associated with greater sensitivity to threats regarding their masculine identity (Bock \& Brown, 2021; Wong et al., 2020). Neither endorsement of traditional masculinity nor gender role conflict emerged as significant moderators influencing the association between loss of social status due to the COVID-19 pandemic and past-month suicide attempt. However, these results should be interpreted with caution and require further replication.

\subsection{Strengths and limitations}

This study presents both strengths and limitations. As a strength, the recruitment and assessment of the sample took place in a condensed time frame of 1.5 months from March 15 till April 28, 2021. Thus, the dynamic character of the COVID-19 pandemic could only exert a small influence on the data. At the time of data collection, the pandemic was starting and peaking in its third wave in Switzerland, Germany, and Austria. Therefore, in all Germanspeaking countries of Central Europe, strong state-imposed COVID-19 protection measures were imposed and there were no prospects for lifting those protections, although vaccination campaigns had just started. It was around this period that individual sectors announced major layoff measures, for example in the airline sector. And since loss of social status was captured by only a single item, another strength of the study is that this item is well backed by additional COVID-19-related questions such as financial difficulties or job loss.

However, several limitations must also be highlighted. The most important point to emphasize is the cross-sectional design and relationships could be examined and thus no longitudinal predictions could be made. Although regression models include predictors of a variable in a model, depressive symptoms can be both predictive of social status loss but also result from social status loss. To understand such associations more clearly, a longitudinal design would be necessary as in previous studies (Griffiths et al., 2021; Hertz-Palmor et al., 2021). Since the current used a convenience sample, it is not possible to infer the entire male population from this sample. For example, the sample is relatively young and the majority of 
men have a high level of education. In addition, it can be assumed that men with mental distress are overrepresented in the study due to the specific study title and advertisement referring to Men's Mental Health in Times of COVID-19. This is further reflected by the very high percentage of men reporting suicidal ideation during the past two weeks. Although the survey clearly defined what constituted a suicide attempt, it is not possible to be entirely sure that the recording of suicide attempts was completely accurate. Furthermore, only the last item of the PHQ-9 was used to capture suicidal ideation. This item asks how often someone suffers from thoughts that they would rather be dead or want to harm themselves. In future, more differentiated scales should be used to assess suicidal ideation, where active and passive suicidal ideation are also differentiated. In addition, the time intervals do not match in the recording of past-two-week suicidal ideation and past-month suicidal attempt.

\subsection{Conclusion}

Since the outbreak of the COVID-19 pandemic, the world population has endured enormous suffering and grief for many deceased. However, the economic consequences are continuing to emerge and will do so for the foreseeable future. Due to macro-structural economic consequences caused by the COVID-19 pandemic and major restructuring and numerous layoffs in many economic sectors, a large number of people worldwide will experience a loss of social status. In addition to loss of social status, other related consequences include loss of purpose, routine, and threats to provider and protector gender roles, with serious consequences for the mental health of men and their families. Men with high traditional masculinity as well as increased depression symptoms are particularly at risk of experiencing a subjective loss of social status due to the COVID-19 pandemic. Furthermore, men with an experienced loss of social status due to the COVID-19 pandemic are at substantially increased risk of becoming suicidal and attempting suicide. In the aftermath of the most acute phase of the COVID-19 pandemic, health care policy should specifically target men with experienced status loss due to the COVID-19 pandemic in suicide prevention programs and swiftly design mental health care campaigns tailored to the group of men with high traditional masculinity.

Author contributions: Design and conceptualization of the study: AW, JG, UE, AH, RP; Participant recruitment and testing: AW, JG, ST; Data analysis and visualization: LE, AW; Data 
interpretation: AW, LE, AH, RP; Writing of the first draft: AW, LE, ST; Editing of subsequent versions: $A W, U E, A H, R P, J S O, J L O$.

Declaration of interest: The authors declare no conflict of interest.

Role of funding source: There was no specific funding for this research. 


\section{References}

American Psychiatric Association. (2013). Diagnostic and statistical manual of mental disorders (DSM-5 $\left.{ }^{\circledR}\right)$ (5th ed.). American Psychiatric Pub.

Ammerman, B. A., Burke, T. A., Jacobucci, R., \& McClure, K. (2021). Preliminary investigation of the association between COVID-19 and suicidal thoughts and behaviors in the U.S. Journal of Psychiatric Research, 134(December 2020), 32-38. https://doi.org/10.1016/j.jpsychires.2020.12.037

Andreeva, E., Magnusson Hanson, L. L., Westerlund, H., Theorell, T., \& Brenner, M. H. (2015). Depressive symptoms as a cause and effect of job loss in men and women: Evidence in the context of organisational downsizing from the Swedish Longitudinal Occupational Survey of Health. BMC Public Health, 15(1), 1-11. https://doi.org/10.1186/s12889-0152377-y

Bem, S. L. (1974). The measurement of psychological androgyny. Journal of Consulting and Clinical Psychology, 42(2), 155-162. https://doi.org/10.1037/h0036215

Benke, C., Autenrieth, L. K., Asselmann, E., \& Pané-Farré, C. A. (2020). Lockdown, quarantine measures, and social distancing: Associations with depression, anxiety and distress at the beginning of the COVID-19 pandemic among adults from Germany. Psychiatry Research, 293, 113462.

Blakely, T. A., Collings, S. C. D., \& Atkinson, J. (2003). Unemployment and suicide. Evidence for a causal association? Journal of Epidemiology \& Community Health, 57(8), 594-600.

Bock, J. E., \& Brown, R. P. (2021). To be liked or feared: Honor-oriented men's sensitivity to masculine reputation concerns depends on status-seeking strategy. Personality and Individual Differences, 173(August 2020), 11-14.

https://doi.org/10.1016/j.paid.2020.110615

Bosson, J. K., \& Vandello, J. A. (2011). Precarious manhood and its links to action and aggression. Current Directions in Psychological Science, 20(2), 82-86.

Brown, M. B., \& Forsythe, A. B. (1974). Robust tests for the equality of variances. Journal of the American Statistical Association, 69(346), 364-367.

https://doi.org/10.1080/01621459.1974.10482955

Chen, H., Cohen, P., \& Chen, S. (2010). How big is a big odds ratio? Interpreting the magnitudes of odds ratios in epidemiological studies. Communications in Statistics: Simulation and Computation, 39(4), 860-864. 
https://doi.org/10.1080/03610911003650383

Coleman, D. (2015). Traditional Masculinity as a Risk Factor for Suicidal Ideation: CrossSectional and Prospective Evidence from a Study of Young Adults. Archives of Suicide Research, 19(3), 366-384. https://doi.org/10.1080/13811118.2014.957453

Coleman, D., Feigelman, W., \& Rosen, Z. (2020). Association of High Traditional Masculinity and Risk of Suicide Death: Secondary Analysis of the Add Health Study. JAMA Psychiatry, 77(4), 435-437. https://doi.org/10.1001/jamapsychiatry.2019.4702

Cook, R. D. (1977). Detection of influential observation in linear regression. Technometrics, 19(1), 15-18. https://doi.org/10.1080/00401706.1977.10489493

Creed, P. A., \& Macintyre, S. R. (2001). The relative effects of deprivation of the latent and manifest benefits of employment on the well-being of unemployed people. Journal of Occupational Health Psychology, 6(4), 324.

Cundiff, J. M., Smith, T. W., Uchino, B. N., \& Berg, C. A. (2013). Subjective social status: Construct validity and associations with psychosocial vulnerability and self-rated health. International Journal of Behavioral Medicine, 20(1), 148-158. https://doi.org/10.1007/s12529-011-9206-1

Dahl, J., \& Cook, J. (2020). Masculinity May Be an Important, Unstable Self-Concept that Men Psychologically Defend. (Unpublished Manuscript - Preprint), January.

Eales, M. J. (1989). Shame among unemployed men. Social Science and Medicine, 28(8), 783-789. https://doi.org/10.1016/0277-9536(89)90107-X

Eggenberger, L., Fordschmid, C., Ludwig, C., Weber, S., Grub, J., Komlenac, N., \& Walther, A. (2021). Men's Psychotherapy Use, Male Role Norms, and Male-Typical Depression Symptoms: Examining 716 Men and Women Experiencing Psychological Distress. Behavioral Sciences, 11(6), 83.

Euteneuer, F., Süssenbach, P., Schäfer, S. J., \& Rief, W. (2015). Subjective social status. MacArthur scales for the assessment of subjective social status in the social environment (SSS-U) and in Germany (SSS-D). Verhaltenstherapie, 25, 229-232. https://doi.org/10.1159/000371558

Fox, J., \& Monette, G. (1992). Generalized collinearity diagnostics. Journal of the American Statistical Association, 87(417), 178-183. https://doi.org/10.1080/01621459.1992.10475190

Fox, J., \& Sanford, W. (2019). An \{R\} Companion to Applied Regression, Third Edition. Sage. 
Garcy, A. M., \& Vågerö, D. (2013). Unemployment and suicide during and after a deep recession: a longitudinal study of 3.4 million Swedish men and women. American Journal of Public Health, 103(6), 1031-1038.

Gerdes, Z. T., \& Levant, R. F. (2018). Complex Relationships Among Masculine Norms and Health/Well-Being Outcomes: Correlation Patterns of the Conformity to Masculine Norms Inventory Subscales. American Journal of Men's Health, 12(2), 229-240. https://doi.org/10.1177/1557988317745910

Gratz, K. L., Tull, M. T., Richmond, J. R., Edmonds, K. A., Scamaldo, K. M., \& Rose, J. P. (2020). Thwarted belongingness and perceived burdensomeness explain the associations of COVID-19 social and economic consequences to suicide risk. Suicide and LifeThreatening Behavior, 50(6), 1140-1148.

Griffiths, D., Sheehan, L., van Vreden, C., Petrie, D., Grant, G., Whiteford, P., Sim, M. R., \& Collie, A. (2021). The Impact of Work Loss on Mental and Physical Health During the COVID-19 Pandemic: Baseline Findings from a Prospective Cohort Study. Journal of Occupational Rehabilitation, 0123456789. https://doi.org/10.1007/s10926-021-099587

Hayes, A. F. (2013). Introduction to mediation, moderation, and conditional process analysis: A regression-based approach. New York, NY: Guilford Press.

Hertz-Palmor, N., Moore, T. M., Gothelf, D., DiDomenico, G. E., Dekel, I., Greenberg, D. M., Brown, L. A., Matalon, N., Visoki, E., White, L. K., Himes, M. M., Schwartz-Lifshitz, M., Gross, R., Gur, R. C., Gur, R. E., Pessach, I. M., \& Barzilay, R. (2021). Association among income loss, financial strain and depressive symptoms during COVID-19: Evidence from two longitudinal studies. Journal of Affective Disorders, 291(April), 1-8. https://doi.org/10.1016/j.jad.2021.04.054

Iñiguez, S. D., Flores-Ramirez, F. J., Riggs, L. M., Alipio, J. B., Garcia-Carachure, I., Hernandez, M. A., Sanchez, D. O., Lobo, M. K., Serrano, P. A., \& Braren, S. H. (2018). Vicarious social defeat stress induces depression-related outcomes in female mice. Biological Psychiatry, 83(1), 9-17.

Johnson, W., \& McCoy, N. (2000). Self-confidence, self-esteem, and assumption of sex role in young men and women. Perceptual and Motor Skills, 90(3), 751-756.

Kawohl, W., \& Nordt, C. (2020). COVID-19, unemployment, and suicide. The Lancet Psychiatry, 7(5), 389-390. https://doi.org/10.1016/S2215-0366(20)30141-3 
Komlenac, N., Siller, H., Bliem, H. R., \& Hochleitner, M. (2018). Validation of the internal structure of a German-language version of the gender role conflict scale - Short form. Frontiers in Psychology, 9(JUL), 1-5. https://doi.org/10.3389/fpsyg.2018.01161

Kroenke, K., Spitzer, R. L., \& Williams, J. B. W. (2001). The PHQ-9: validity of a brief depression severity measure. Journal of General Internal Medicine, 16(9), 606-613.

Levant, R. F., Hall, R. J., \& Rankin, T. J. (2013). Male Role Norms Inventory-Short Form (MRNI-SF): Development, confirmatory factor analytic investigation of structure, and measurement invariance across gender. Journal of Counseling Psychology, 60(2), 228.

Levant, R. F., \& Richmond, K. (2015). The gender role strain paradigm and masculinity ideologies. APA Handbook of Men and Masculinities., 23-49. https://doi.org/10.1037/14594-002

Levis, B., Sun, Y., He, C., Wu, Y., Krishnan, A., Bhandari, P. M., Neupane, D., Imran, M., Brehaut, E., Negeri, Z., Fischer, F. H., Benedetti, A., \& Thombs, B. D. (2020). Accuracy of the PHQ-2 Alone and in Combination with the PHQ-9 for Screening to Detect Major Depression: Systematic Review and Meta-analysis. JAMA - Journal of the American Medical Association, 323(22), 2290-2300. https://doi.org/10.1001/jama.2020.6504

Lin, J., Zou, L., Lin, W., Becker, B., Yeung, A., \& Cuijpers, P. (2021). Does gender role explain a high risk of depression? A meta-analytic review of 40 years of evidence. 294(January), 261-278.

Lippa, R. A., Martin, L. R., \& Friedman, H. S. (2000). Gender-related individual differences and mortality in the terman longitudinal study: Is masculinity hazardous to your health? Personality and Social Psychology Bulletin, 26(12), 1560-1570. https://doi.org/10.1177/01461672002612010

Long, V. O. (1986). Relationship of masculinity to self-esteem and self-acceptance in female professionals, college students, clients, and victims of domestic violence. Journal of Consulting and Clinical Psychology, 54(3), 323.

Louzon, S. A., Bossarte, R., McCarthy, J. F., \& Katz, I. R. (2016). Does suicidal ideation as measured by the PHQ-9 predict suicide among VA patients? Psychiatric Services, 67(5), 517-522.

Mahalik, J. R., Bianca, M. Di, \& Harris, M. P. (2021). Men's attitudes toward mask-wearing during COVID-19: Understanding the complexities of mask-ulinity. Journal of Health Psychology. https://doi.org/10.1177/1359105321990793 
Mangiafico, S. (2021). rcompanion: Functions to support extension education program evaluation (2.4.0).

Martikainen, P. T., \& Valkonen, T. (1996). Excess mortality of unemployed men and women during a period of rapidly increasing unemployment. The Lancet, 348(9032), 909-912.

Martin, A., Rief, W., Klaiberg, A., \& Braehler, E. (2006). Validity of the brief patient health questionnaire mood scale (PHQ-9) in the general population. General Hospital Psychiatry, 28(1), 71-77.

Michniewicz, K. S., Vandello, J. A., \& Bosson, J. K. (2014). Men's (Mis)Perceptions of the Gender Threatening Consequences of Unemployment. Sex Roles, 70(3-4), 88-97. https://doi.org/10.1007/s11199-013-0339-3

Mirowsky, J., \& Ross, C. E. (1995). Sex differences in distress: Real or artifact? American Sociological Review, 60, 449-468.

Na, P. J., Yaramala, S. R., Kim, J. A., Kim, H., Goes, F. S., Zandi, P. P., Voort, J. L. Vande, Sutor, B., Croarkin, P., \& Bobo, W. V. (2018). The PHQ-9 Item 9 based screening for suicide risk: a validation study of the Patient Health Questionnaire (PHQ)- 9 Item 9 with the Columbia Suicide Severity Rating Scale (C-SSRS). Journal of Affective Disorders, 232, 3440.

Nordt, C., Warnke, I., Seifritz, E., \& Kawohl, W. (2015). Modelling suicide and unemployment: A longitudinal analysis covering 63 countries, 2000-11. The Lancet Psychiatry, 2(3), 239245. https://doi.org/10.1016/S2215-0366(14)00118-7

O’Heron, C. A., \& Orlofsky, J. L. (1990). Stereotypic and nonstereotypic sex role trait and behavior orientations, gender identity, and psychological adjustment. Journal of Personality and Social Psychology, 58(1), 134.

O’Neil, J. M. (2013). Gender role conflict research 30 years later: An evidence-based diagnostic schema to assess boys and men in counseling. Journal of Counseling and Development, 91(4), 490-498. https://doi.org/10.1002/j.1556-6676.2013.00122.x

O'Neil, J. M. (2015). Men's gender role conflict: Psychological costs, consequences, and an agenda for change. American Psychological Association.

O’Neil, J. M., Helms, B. J., Gable, R. K., David, L., \& Wrightsman, L. S. (1986). Gender-Role Conflict Scale: College men's fear of femininity. Sex Roles, 14(5), 335-350.

Ogrodniczuk, J. S., Rice, S. M., Kealy, D., Seidler, Z. E., Delara, M., \& Oliffe, J. L. (2021). Psychosocial impact of the COVID-19 pandemic: a cross-sectional study of online help- 
seeking Canadian men. Postgraduate Medicine, 00(00), 1-10.

https://doi.org/10.1080/00325481.2021.1873027

Operario, D., Adler, N. E., \& Williams, D. R. (2004). Subjective social status: Reliability and predictive utility for global health. Psychology and Health, 19(2), 237-246. https://doi.org/10.1080/08870440310001638098

Ozamiz-Etxebarria, N., Idoiaga Mondragon, N., Dosil Santamaría, M., \& Picaza Gorrotxategi, M. (2020). Psychological symptoms during the two stages of lockdown in response to the COVID-19 outbreak: an investigation in a sample of citizens in Northern Spain. Frontiers in Psychology, 11, 1491.

Paul, K. I., \& Batinic, B. (2010). The need for work: Jahoda's latent functions of employment in a representative sample of the German population. Journal of Organizational Behavior, 31(1), 45-64.

Pirkis, J., Spittal, M. J., Keogh, L., Mousaferiadis, T., \& Currier, D. (2017). Masculinity and suicidal thinking. Social Psychiatry and Psychiatric Epidemiology, 52(3), 319-327. https://doi.org/10.1007/s00127-016-1324-2

$R$ Core Team. (2020). $R$ : A language and environment for statistical computing (4.0.3). $R$ Foundation for Statistical Computing, Vienna, Austria.

Rantakeisu, U., Starrin, B., \& Hagquist, C. (1997). Unemployment, shame and ill health - An exploratory study. International Journal of Social Welfare, 6(1), 13-23. https://doi.org/10.1111/j.1468-2397.1997.tb00160.x

Revelle, W. (2020). psych: Procedures for personality and psychological research (2.1.3). Northwestern University, Evanston, Illinois, USA.

Rice, S. M., Fallon, B. J., Aucote, H. M., \& Möller-Leimkühler, A. M. (2013). Development and preliminary validation of the male depression risk scale: Furthering the assessment of depression in men. Journal of Affective Disorders, 151(3), 950-958. https://doi.org/10.1016/j.jad.2013.08.013

Rice, S. M., Ogrodniczuk, J. S., Kealy, D., Seidler, Z. E., Dhillon, H. M., \& Oliffe, J. L. (2019). Validity of the Male Depression Risk Scale in a representative Canadian sample: sensitivity and specificity in identifying men with recent suicide attempt. Journal of Mental Health, 28(2), 132-140. https://doi.org/10.1080/09638237.2017.1417565

Riumallo-Herl, C., Basu, S., Stuckler, D., Courtin, E., \& Avendano, M. (2014). Job loss, wealth and depression during the Great Recession in the USA and Europe. International Journal 
of Epidemiology, 43(5), 1508-1517.

Salari, N., Hosseinian-Far, A., Jalali, R., Vaisi-Raygani, A., Rasoulpoor, S., Mohammadi, M., Rasoulpoor, S., \& Khaledi-Paveh, B. (2020). Prevalence of stress, anxiety, depression among the general population during the COVID-19 pandemic: a systematic review and meta-analysis. Globalization and Health, 16(1), 1-11.

Sher, L. (2006). Per capita income is related to suicide rates in men but not in women. The Journal of Men's Health \& Gender, 3(1), 39-42.

https://doi.org/10.1016/j.jmhg.2005.04.016

Sher, L. (2020). The impact of the COVID-19 pandemic on suicide rates. QJM : Monthly Journal of the Association of Physicians, 113(10), 707-712. https://doi.org/10.1093/qjmed/hcaa202

Siegrist, J. (2000). Place, social exchange and health: proposed sociological framework. Social Science \& Medicine, 51(9), 1283-1293.

Tiggemann, M., \& Winefield, A. H. (1984). The effects of unemployment on the mood, selfesteem, locus of control, and depressive affect of school-leavers. Journal of Occupational Psychology, 57(1), 33-42.

Troche, S., \& Rammsayer, T. (2011). Eine Revision des deutschsprachigen Bem Sex-Role Inventory. Klinische Diagnostik Und Evaluation, 4, 262-283.

Van Doorn, G., Teese, R., \& Gill, P. R. (2021). Prospective associations between hegemonic masculinity and incident depression/depressive symptoms: Results from a national sample of Australian emerging adult men. Personality and Individual Differences, 179(March). https://doi.org/10.1016/j.paid.2021.110899

Vandello, J. A., \& Bosson, J. K. (2013). Hard won and easily lost: A review and synthesis of theory and research on precarious manhood. Psychology of Men and Masculinity, 14(2), 101-113. https://doi.org/10.1037/a0029826

Walther, A, Grub, J., Ehlert, U., Wehrli, S., Rice, S., Seidler, Z. E., \& Debelak, R. (2021). Male depression risk, psychological distress, and psychotherapy uptake: validation of the German version of the male depression risk scale. Journal of Affective Disorders Reports, 100107. https://doi.org/https://doi.org/10.1016/j.jadr.2021.100107

Walther, Andreas, \& Seidler, Z. E. (2020). Männliche Formen der Depression und deren Behandlung. PiD-Psychotherapie Im Dialog, 21(04), 40-45. https://doi.org/10.1055/a0987-5902 
Wester, S. R., Vogel, D. L., O’Neil, J. M., \& Danforth, L. (2012). Development and evaluation of the Gender Role Conflict Scale Short Form (GRCS-SF). Psychology of Men \& Masculinity, 13(2), 199.

Wickham, H. (2016). ggplot2: Elegant graphics for data analysis. Springer-Verlag, New York.

Wong, Y. J., Granderson, R. M., Zounlome, N. O. O., McCullough, K. M., Hyman, J. E., \& Schwabe, S. B. (2020). The Assessment of Subjective Masculine Norms in the United States. Psychology of Men and Masculinity, 21(4), 545-557. https://doi.org/10.1037/men0000254

Wong, Y. J., Ho, M. H. R., Wang, S. Y., \& Miller, I. S. K. (2017). Meta-analyses of the relationship between conformity to masculine norms and mental health-related outcomes. Journal of Counseling Psychology, 64(1), 80-93. https://doi.org/10.1037/cou0000176 
Table 1. Descriptive Statistics for the Sample

\begin{tabular}{|c|c|c|c|c|c|c|c|c|c|}
\hline & \multicolumn{2}{|c|}{ Total $(N=490)$} & \multicolumn{2}{|c|}{ Status Loss $(N=72)$} & \multicolumn{2}{|c|}{ No Status Loss $(N=418)$} & \multirow[b]{2}{*}{$t(d f)$} & \multirow[b]{2}{*}{$\chi^{2}(d f)$} & \multirow[b]{2}{*}{$p$} \\
\hline & $N(\%)$ & $M(S D)$ & $N(\%)$ & $M(S D)$ & $N(\%)$ & $M(S D)$ & & & \\
\hline Age & & $25.7(9.8)$ & & $25.7(8.6)$ & & $25.7(10.0)$ & $0.04(448)$ & & .971 \\
\hline Nationality & & & & & & & & $6.82(6)$ & .338 \\
\hline Swiss & $71(14.5)$ & & 10 (13.9) & & $61(14.6)$ & & & & \\
\hline German & $358(73.1)$ & & $52(72.2)$ & & $306(73.2)$ & & & & \\
\hline Austrian & $43(8.8)$ & & $7(9.7)$ & & $36(8.6)$ & & & & \\
\hline Luxembourger & $4(0.8)$ & & $0(0)$ & & $4(1.0)$ & & & & \\
\hline Liechtensteiner & $1(0.2)$ & & $0(0)$ & & $1(0.2)$ & & & & \\
\hline Belgian & $1(0.2)$ & & $1(1.4)$ & & $0(0)$ & & & & \\
\hline Other & $12(2.4)$ & & $2(2.8)$ & & $10(2.4)$ & & & & \\
\hline Sexual orientation & & & & & & & & 3.21 (4) & .524 \\
\hline Heterosexual-identified & $361(73.7)$ & & 55 (76.4) & & $306(73.2)$ & & & & \\
\hline Gay/Lesbian-identified & $39(8.0)$ & & $3(4.2)$ & & $36(8.6)$ & & & & \\
\hline Bisexual-identified & $67(13.7)$ & & $12(16.7)$ & & $55(13.2)$ & & & & \\
\hline Asexual-identified & $5(1.0)$ & & $0(0)$ & & $5(1.2)$ & & & & \\
\hline Other & $18(3.7)$ & & $2(2.8)$ & & $16(3.8)$ & & & & \\
\hline Marital status & & & & & & & & $0.28(2)$ & .868 \\
\hline Single & $311(63.5)$ & & 46 (63.9) & & $265(63.4)$ & & & & \\
\hline In a relationship & $168(34.3)$ & & $25(34.7)$ & & $143(34.2)$ & & & & \\
\hline $\begin{array}{l}\text { Separated after } \\
\text { permanent relationship }\end{array}$ & $11(2.2)$ & & $1(1.4)$ & & $10(2.4)$ & & & & \\
\hline Education & & & & & & & & $2.02(3)$ & .568 \\
\hline None completed & $10(2.0)$ & & $0(0)$ & & $10(2.4)$ & & & & \\
\hline Secondary education & 348 (71.0) & & $53(73.6)$ & & 295 (70.6) & & & & \\
\hline Tertiary education & $106(21.6)$ & & $16(22.2)$ & & $90(21.5)$ & & & & \\
\hline Other & $26(5.3)$ & & $3(4.2)$ & & $23(5.5)$ & & & & \\
\hline $\begin{array}{l}\text { Yearly household income } \\
\text { (in CHF) }\end{array}$ & & & & & & & & $9.05(2)$ & $.011^{*}$ \\
\hline$<25^{\prime} 000$ & $233(47.6)$ & & 46 (63.9) & & $187(44.7)$ & & & & \\
\hline
\end{tabular}




\section{$25^{\prime} 000-50^{\prime} 000$ \\ $>50^{\prime} 000$ \\ Subjective Social Status}

92 (18.8)

165 (33.7)

9 (12.5)

17 (23.6)

High

$339(69.2)$

$151(30.8)$

$34(6.9)$

Corona Infection ${ }^{\dagger}$

Due to CV19 Pandemic ${ }^{\dagger}$

Financial problems

Job insecurity

Job loss

Employment office

Existential threat

Suicide Attempt ${ }^{\dagger}$

past month

Lifetime

Suicidal Ideation $^{\dagger}$

Psychological Disorder $^{\dagger}$

Psychotherapy $^{\dagger}$

Medication $^{\dagger}$

Depression Cutoff

PHQ-9 ( $\geq 10)$

MDRS-22 $(\geq 51)$

\section{PHQ-9 ${ }^{\text {a }}$}

MDRS-22 ${ }^{b}$

BSRI $(m)^{c}$

MRNI ${ }^{\text {d }}$

GRCS ${ }^{\mathrm{a}}$

\section{0 (20.4) \\ $112(22.9)$ \\ 41 (8.4) \\ $34(6.9)$ \\ 95 (19.4)}

$$
\begin{gathered}
20(4.1) \\
114(23.3) \\
240(49.0) \\
117(23.9) \\
95(19.4) \\
64(13.1)
\end{gathered}
$$

$322(65.7)$

67 (13.7)

$12.6(6.6)$
$29.2(20.6)$
$62.5(14.6)$
$45.6(21.4)$
$47.0(12.6)$

\section{4 (61.1)}

28 (38.9)

$5(6.9)$

42 (58.3)

21 (29.2)

19 (26.4)

37 (51.4)

$$
\begin{gathered}
8(11.1) \\
24(33.3) \\
47(65.3) \\
20(27.8) \\
12(16.7) \\
7(9.7) \\
61(84.7) \\
22(30.6)
\end{gathered}
$$

43 (59.7)
83 (19.9)

148 (35.4)

2.15 (1)

.142

295 (70.6)

123 (29.4)

$29(6.9)$

58 (13.9)

$69(16.5)$

20 (4.8)

15 (3.6)

$58(13.9)$

\begin{tabular}{|c|c|c|c|}
\hline & & 2.15 (1) & .142 \\
\hline & & $1(1)$ & 1 \\
\hline & & $72.02(1)$ & $<.001^{* * *}$ \\
\hline & & $62.62(1)$ & $<.001^{* * *}$ \\
\hline & & 44.50 (1) & $<.001^{* * *}$ \\
\hline & & 45.98 (1) & $<.001^{* * *}$ \\
\hline & & 52.93 (1) & $<.001^{* * *}$ \\
\hline & & 8.65 (1) & $.003^{* *}$ \\
\hline & & 4.15 (1) & $.042^{*}$ \\
\hline & & $8.22(1)$ & $.004^{* *}$ \\
\hline & & 9.48 (1) & .490 \\
\hline & & $0.22(1)$ & .638 \\
\hline & & $0.52(1)$ & .471 \\
\hline & & $12.56(1)$ & $<.001^{* * *}$ \\
\hline & & $18.74(1)$ & $<.001^{* * *}$ \\
\hline $12.0(6.5)$ & 4.90 (488) & & $<.001^{* * *}$ \\
\hline 26.8 (18.7) & $5.38(85.4)$ & & $<.001^{* * *}$ \\
\hline 61.8 (14.4) & 2.25 (488) & & $.025^{*}$ \\
\hline $43.8(20.0)$ & $3.83(85.7)$ & & $<.001^{* * *}$ \\
\hline 45.9 (11.9) & 4.49 (88.6) & & $<.001^{* * *}$ \\
\hline
\end{tabular}

12 (2.9)

90 (21.5)

193 (46.2)

97 (23.2)

83 (19.9)

57 (13.6)

261 (62.4)

45 (10.8)

16.0 (6.4)

43.3 (24.9)

56.2 (26.2)

53.8 (14.3)
$66.0(15.6)$

Note. $N=$ number of participants, $M=$ mean, $S D=$ standard deviation, $t=\mathrm{t}$-statistic, $d f=$ degrees of freedom, $\chi^{2}=$ chi-square test-statistic, $p=p$-value. Subjective social status was dichotomized as above (= high) and below (= low) the middle of the scale used in that question.

${ }^{+}$Assessed in self-report

a PHQ-9 = Patient Health Questionnaire $-9 ;{ }^{b}$ MDRS-22 = Male Depression Risk Scale $-22 ;{ }^{c}$ BSRI $(m)=$ Bem Sex-Role Inventory $\left(m=\right.$ masculinity subscale); ${ }^{d}$ MRNI $=$ Male Role Norms Inventory; ${ }^{\mathrm{e}} \mathrm{GRCS}=$ Gender Role Conflict Scale

${ }^{*}=p<.05,{ }^{* *}=p<.01,{ }^{* * *}=p<.001$ 


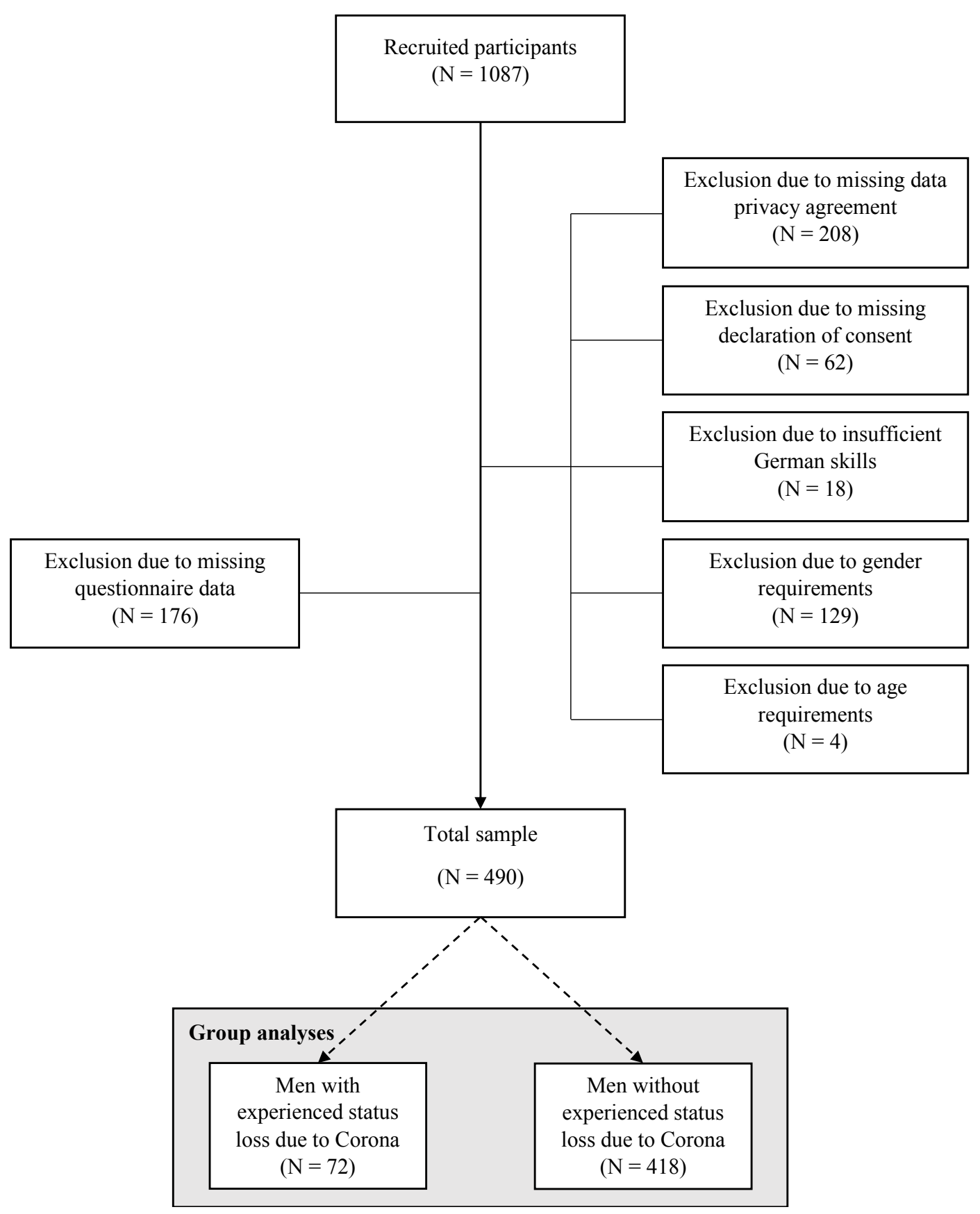

Figure 1. Flow diagram of the inclusion and exclusion process ( $N=$ number of participants) 


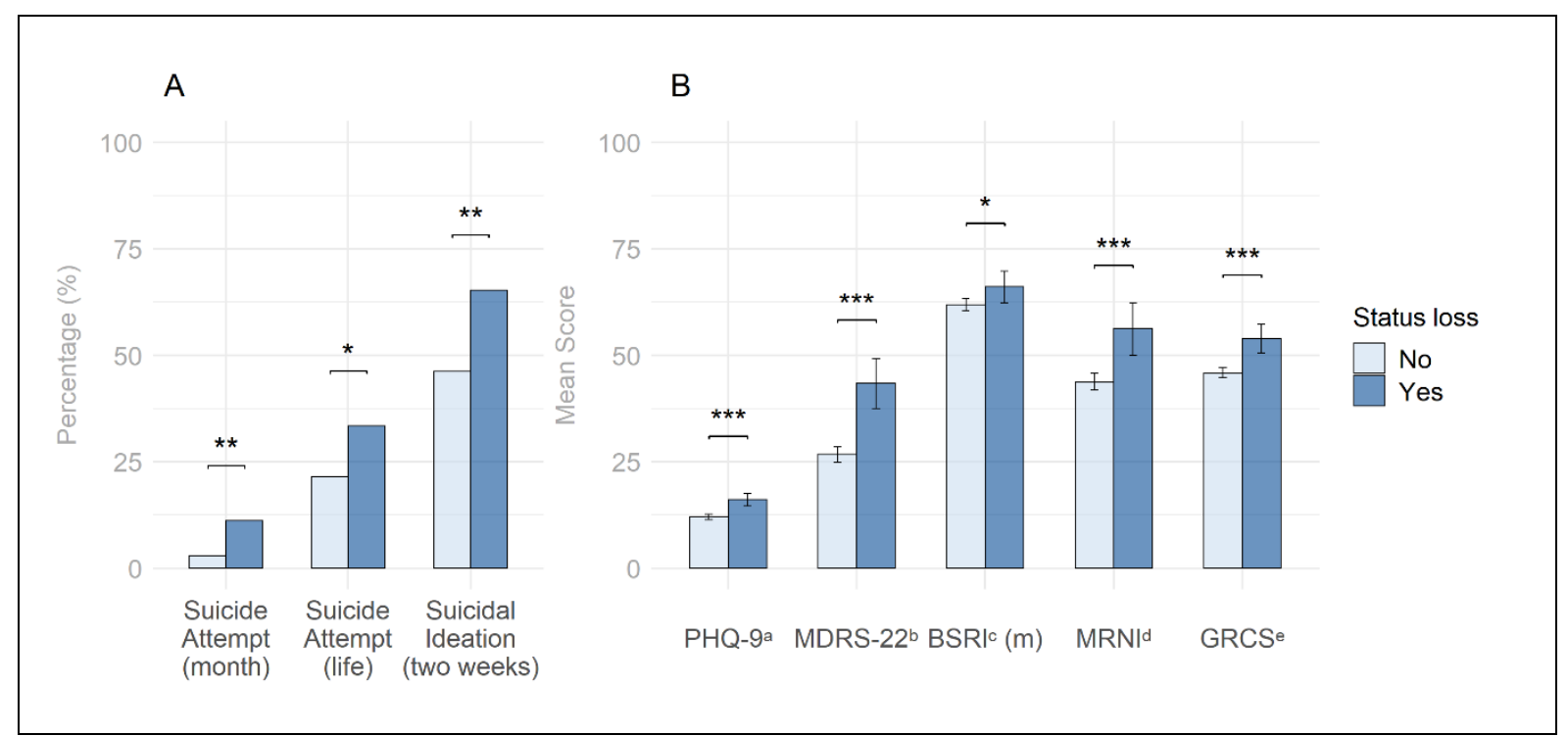

Figure 2. Group Differences between men with and without Experienced Status loss

Note. month $=$ in the past month, life $=$ during lifetime, two weeks $=$ in the past two weeks.

${ }^{\mathrm{a}}$ PHQ-9 = Patient Health Questionnaire - 9; ${ }^{\mathrm{b}}$ MDRS-22 = Male Depression Risk Scale - 22; ${ }^{\mathrm{c}} \mathrm{BSRI}$ $(m)=$ Bem Sex-Role Inventory ( $m=$ masculinity subscale); ${ }^{\mathrm{d}} \mathrm{MRNI}=$ Male Role Norms Inventory; ${ }^{\mathrm{e}}$ GRCS $=$ Gender Role Conflict Scale ${ }^{*}=p<.05,{ }^{* *}=p<.01,{ }^{* * *}=p<.001$ 


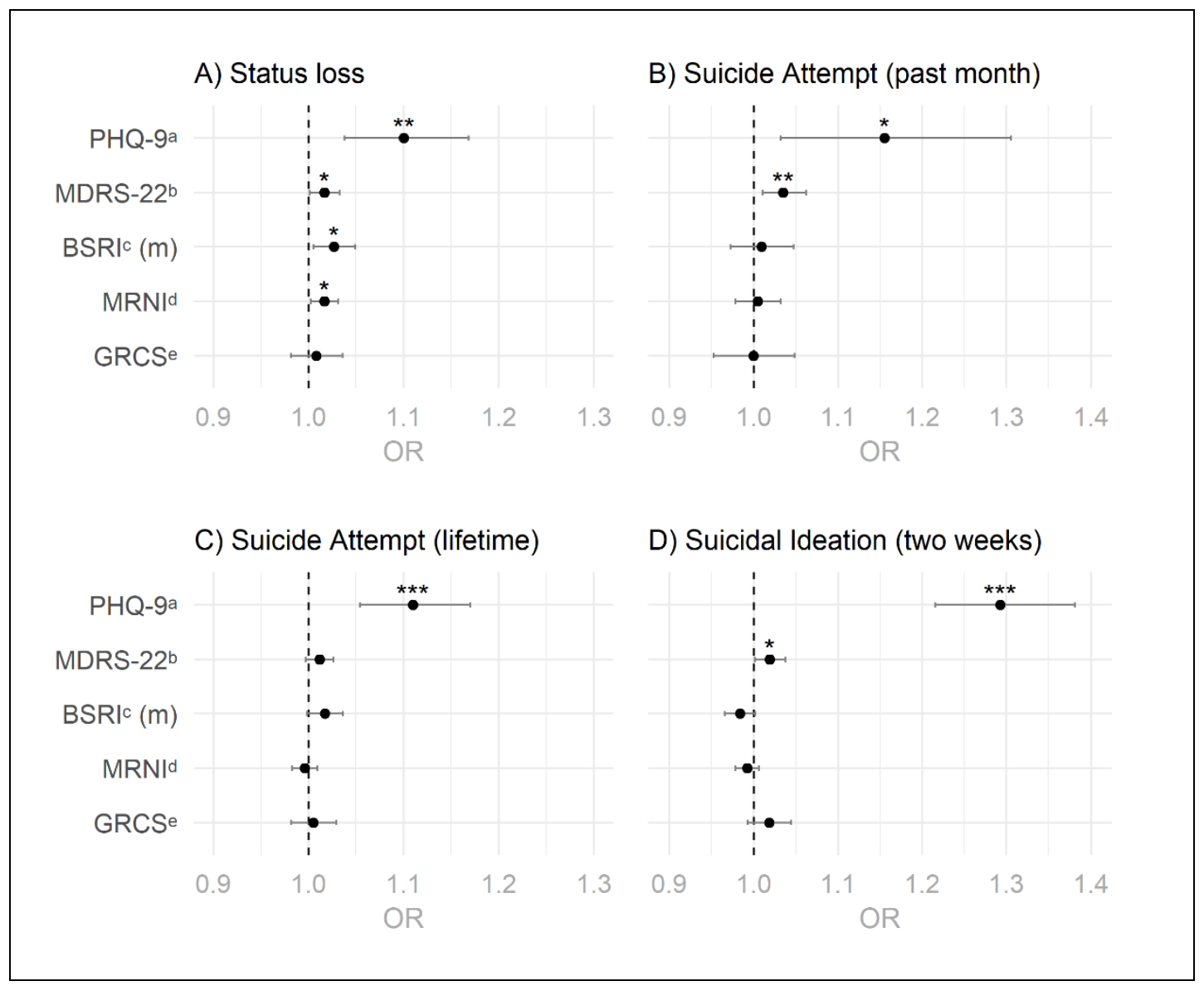

Figure 3. Odds Ratios for Status loss, Suicide Attempt, and Suicidal Ideation Note. $O R=$ Odds Ratio; ${ }^{\text {a }}$ PHQ-9 = Patient Health Questionnaire $-9 ;{ }^{b}$ MDRS-22 = Male Depression Risk Scale $-22{ }^{c}$ BSRI $(m)=$ Bem Sex-Role Inventory $(m=$ masculinity subscale); ${ }^{\mathrm{d}} \mathrm{MRNI}=$ Male Role Norms Inventory; ${ }^{\mathrm{e}} \mathrm{GRCS}=$ Gender Role Conflict Scale ${ }^{*}=p<.05,{ }^{* *}=p<.01,{ }^{* * *}=p<.001$ 


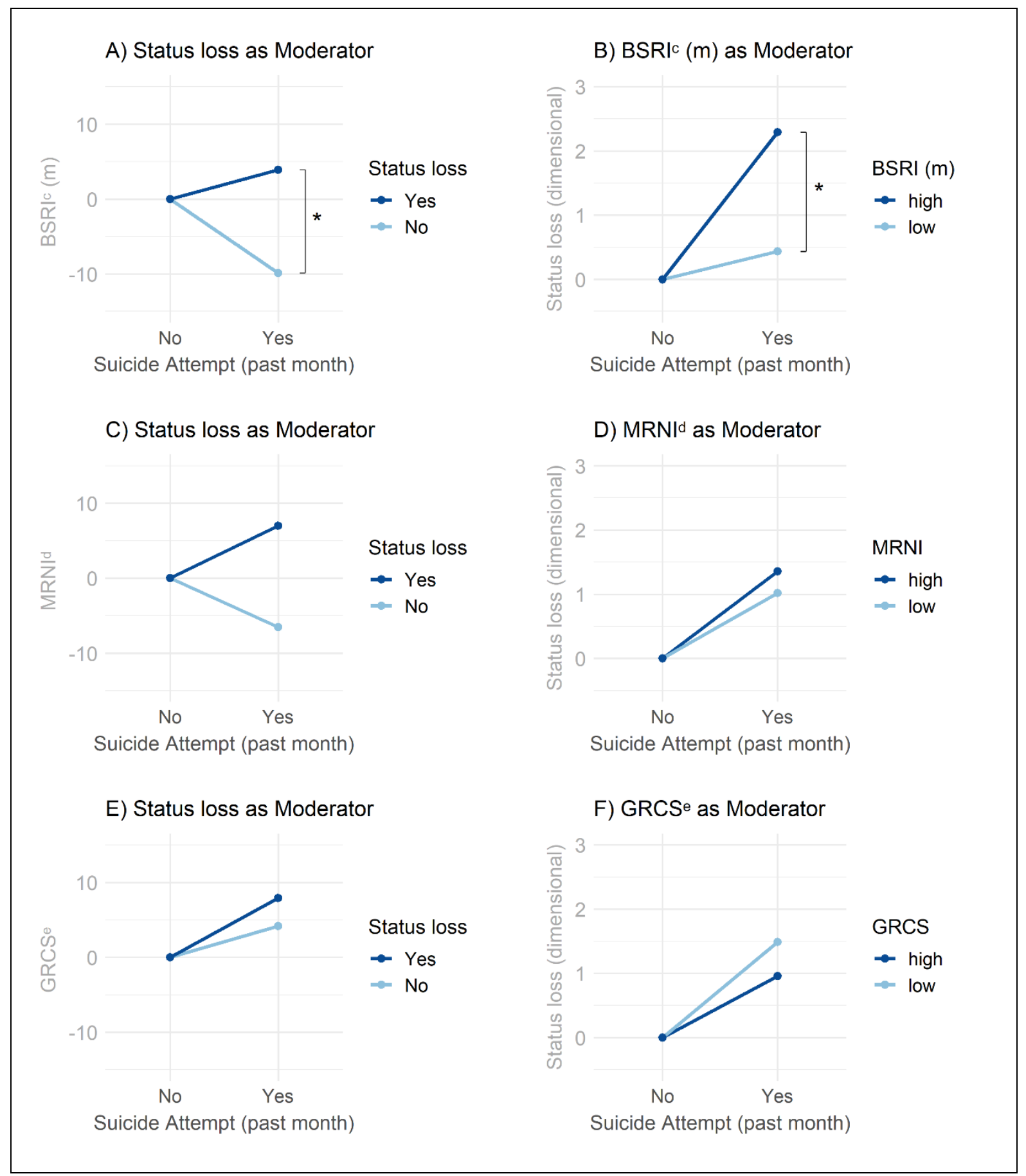

Figure 4. Moderation Effects

Note. Median split was applied to BSRI, MRNI, and GRCS scores for "high" and "low" categories. ${ }^{\mathrm{c}}$ BSRI $(\mathrm{m})=$ Bem Sex-Role Inventory $\left(m=\right.$ masculinity subscale); ${ }^{\mathrm{d}} \mathrm{MRNI}=$ Male Role Norms Inventory; ${ }^{\mathrm{e}} \mathrm{GRCS}=$ Gender Role Conflict Scale 


\section{Status loss due to COVID-19, traditional masculinity, and the prediction of suicidal ideation and recent suicide attempts}

Walther, A. ${ }^{1,{ }^{*}}$, Grub, J. ${ }^{1}$, Tsar, S. ${ }^{1}$, Ehlert, U. ${ }^{1}$, Heald, A. ${ }^{2,3}$, Perrin, R. ${ }^{4}$, Ogrodniczuk, J.S. ${ }^{5}$, Seidler, Z.E. ${ }^{6,7}$, Rice, S.M. ${ }^{6,7}$, Kealy, D. ${ }^{5}$, Oliffe, J.L. ${ }^{8,9}$, Eggenberger, L. ${ }^{1}$

${ }^{1}$ Clinical Psychology and Psychotherapy, University of Zurich, Zurich, Switzerland

${ }^{2}$ The School of Medicine and Manchester Academic Health Sciences Centre, University of Manchester, UK

${ }^{3}$ Department of Endocrinology and Diabetes, Salford Royal Hospital, Salford, UK

${ }^{4}$ The School of Health Sciences, University of Manchester, Manchester, UK

${ }^{5}$ Department of Psychiatry, University of British Columbia, Vancouver, Canada

${ }^{6}$ Orygen, Melbourne, VIC, Australia

${ }^{7}$ Centre for Youth Mental Health, The University of Melbourne, Parkville, VIC, Australia

${ }^{8}$ School of Nursing, University of British Columbia, Vancouver, Canada

${ }^{9}$ Department of Nursing, University of Melbourne, Parkville, VIC, Australia

* corresponding author

\section{Supplementary material}

\section{Content}

S-Table 1: Group Comparisons between men with and without Experienced

Status loss 
S-Table 1. Group Comparisons between men with and without Experienced Status loss

\begin{tabular}{|c|c|c|c|c|}
\hline \multirow[t]{2}{*}{ Variable } & \multirow{2}{*}{$\frac{\text { No status loss }}{\mathrm{N}(\%)}$} & \multirow{2}{*}{$\frac{\text { Status loss }}{\mathrm{N}(\%)}$} & \multicolumn{2}{|c|}{ test statistics } \\
\hline & & & $z$-score (df) & $p$-value \\
\hline $\begin{array}{l}\text { Suicide Attempt } \\
\text { (past month) }\end{array}$ & $12(2.9)$ & $8(11.1)$ & $3.04(484)$ & $.002^{* *}$ \\
\hline $\begin{array}{l}\text { Suicide Attempt } \\
\text { (lifetime) }\end{array}$ & $90(21.5)$ & 24 (33.3) & $2.01(484)$ & $.044^{*}$ \\
\hline \multirow[t]{2}{*}{$\begin{array}{l}\text { Suicidal Ideation } \\
\text { (past two weeks) }\end{array}$} & 193 (46.2) & $47(65.3)$ & $3.11(484)$ & $.002^{* *}$ \\
\hline & $\mathrm{M}(S D)$ & $\mathrm{M}(S D)$ & t-value (df) & $p$-value \\
\hline PHQ-9 ${ }^{a}$ & $12.0(6.5)$ & $16.0(6.4)$ & $5.43(484)$ & $<.001^{* * *}$ \\
\hline MDRS-22 ${ }^{b}$ & 26.8 (18.7) & $43.3(24.9)$ & $6.77(484)$ & $<.001^{* * *}$ \\
\hline $\operatorname{BSRI}(\mathrm{m})^{\mathrm{c}}$ & $61.9(14.4)$ & $66.0(15.6)$ & 2.20 (484) & $.029^{*}$ \\
\hline MRNI ${ }^{d}$ & $43.8(20.0)$ & $56.2(26.2)$ & $4.72(484)$ & $<.001^{* * *}$ \\
\hline GRCS $^{e}$ & 45.9 (11.9) & $53.9(14.3)$ & $5.08(484)$ & $<.001^{* * *}$ \\
\hline
\end{tabular}

Note. $N=$ Number of participants, $M=$ mean score, $S D=$ standard deviation, $d f=$ degrees of freedom. All calculations were controlled for age, income, education and sexual orientation.

${ }^{\mathrm{a}}$ PHQ-9 = Patient Health Questionnaire - 9; ${ }^{\mathrm{b}}$ MDRS-22 = Male Depression Risk Scale - 22; ${ }^{\mathrm{c}}$ BSRI (m) $=$ Bem Sex-Role Inventory - Masculinity Scale; ${ }^{e}$ GRCS $=$ Gender Role Conflict Scale.

${ }^{*}=\mathrm{p}<.05,{ }^{* *}=\mathrm{p}<.01,{ }^{* * *}=\mathrm{p}<.001$ 
S-Table 2. Summary of binary logistic Regression Models

\begin{tabular}{|c|c|c|c|c|c|}
\hline Outcome & Predictor & $\beta^{1}\left(S E^{1}\right)$ & $p$ & $R^{2}$ & AIC \\
\hline \multirow{5}{*}{ Status loss } & PHQ-9 a & $0.63(0.20)$ & $.002^{* *}$ & & \\
\hline & MDRS-22 ${ }^{b}$ & $0.34(0.16)$ & $.037^{*}$ & & \\
\hline & $\operatorname{BSRI}(\mathrm{m})^{\mathrm{c}}$ & $0.38(0.16)$ & $.017^{*}$ & & \\
\hline & $\mathrm{MRNI}^{\mathrm{d}}$ & $0.35(0.15)$ & $.021^{*}$ & & \\
\hline & GRCS $^{\text {e }}$ & $0.10(0.17)$ & .552 & & \\
\hline Omnibus statistics & & & $<.001^{* * *}$ & .211 & 366.6 \\
\hline \multirow{5}{*}{$\begin{array}{l}\text { Suicide Attempt } \\
\text { (past month) }\end{array}$} & PHQ-9 a & $0.95(0.39)$ & $.015^{*}$ & & \\
\hline & MDRS-22 ${ }^{b}$ & $0.71(0.26)$ & $.006^{* *}$ & & \\
\hline & $\operatorname{BSRI}(\mathrm{m})^{c}$ & $0.14(0.27)$ & .620 & & \\
\hline & $\mathrm{MRNI}^{\mathrm{d}}$ & $0.11(0.29)$ & .713 & & \\
\hline & GRCS $^{\text {e }}$ & $0.01(0.30)$ & .989 & & \\
\hline Omnibus statistics & & & $<.001^{* * *}$ & .321 & 139.4 \\
\hline \multirow{5}{*}{$\begin{array}{l}\text { Suicide Attempt } \\
\text { (lifetime) }\end{array}$} & PHQ-9 ${ }^{\text {a }}$ & $0.69(0.17)$ & $<.001^{* * *}$ & & \\
\hline & MDRS-22 ${ }^{b}$ & $0.23(0.15)$ & .121 & & \\
\hline & $\operatorname{BSRI}(m)^{c}$ & $0.25(0.14)$ & .073 & & \\
\hline & $\mathrm{MRNI}^{\mathrm{d}}$ & $-0.09(0.14)$ & .541 & & \\
\hline & GRCS $^{\mathrm{e}}$ & $0.07(0.15)$ & .661 & & \\
\hline Omnibus statistics & & & $<.001^{* * *}$ & .224 & 472.8 \\
\hline \multirow{5}{*}{$\begin{array}{l}\text { Suicidal Ideation } \\
\text { (past two weeks) }\end{array}$} & PHQ-9 a & $1.70(0.22)$ & $<.001^{* * *}$ & & \\
\hline & MDRS-22 ${ }^{b}$ & $0.39(0.19)$ & $.037^{*}$ & & \\
\hline & $\operatorname{BSRI}(m)^{c}$ & $-0.24(0.14)$ & .079 & & \\
\hline & $\mathrm{MRNI}^{\mathrm{d}}$ & $-0.16(0.16)$ & .297 & & \\
\hline & GRCS $^{\text {e }}$ & $0.23(0.16)$ & .165 & & \\
\hline Omnibus statistics & & & $<.001^{* * *}$ & .551 & 438.1 \\
\hline
\end{tabular}

Note. $\beta=$ estimated regression coefficient, $S E=$ standard error, $p=p$-value, $R^{2}=$ Nagelkerke's maximum-likelihood estimation for pseudo $R$-squared, AIC = Akaike Information Criterion. All calculations were controlled for age, income, education and sexual orientation.

${ }^{1}=$ Reported coefficients are scaled and centered ( $z$-standard.).

${ }^{\mathrm{a}}$ PHQ-9 = Patient Health Questionnaire $-9 ;{ }^{\mathrm{b}}$ MDRS-22 = Male Depression Risk Scale $-22 ;{ }^{\mathrm{c}}$ BSRI (m)

$=$ Bem Sex-Role Inventory - Masculinity Scale; ${ }^{\mathrm{e}}$ GRCS $=$ Gender Role Conflict Scale.

${ }^{*}=p<.05,{ }^{* *}=p<.01,{ }^{* * *}=p<.001$ 